\title{
Assembly and Delivery of Rabbit Capsules for Irradiation of Silicon Carbide Cladding Tube Specimens in the High Flux Isotope Reactor
}

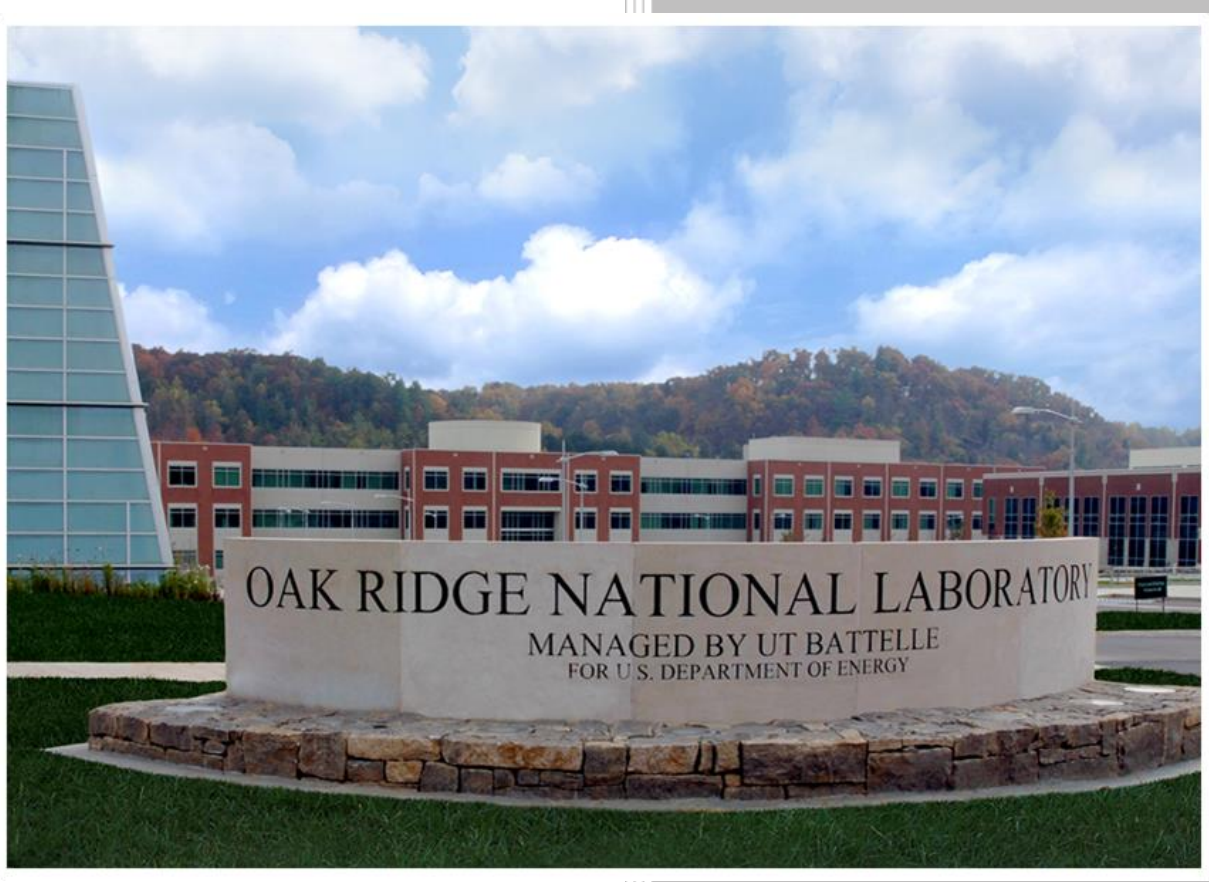

\section{Approved for public release.} Distribution is unlimited.

Christian M. Petrie Takaaki Koyanagi

September 6, 2017 


\title{
DOCUMENT AVAILABILITY
}

Reports produced after January 1, 1996, are generally available free via US Department of Energy (DOE) SciTech Connect.

Website http://www.osti.gov/scitech/

Reports produced before January 1, 1996, may be purchased by members of the public from the following source:

\author{
National Technical Information Service \\ 5285 Port Royal Road \\ Springfield, VA 22161 \\ Telephone 703-605-6000 (1-800-553-6847) \\ TDD 703-487-4639 \\ Fax 703-605-6900 \\ E-mail info@ntis.gov \\ Website http://classic.ntis.gov/
}

Reports are available to DOE employees, DOE contractors, Energy Technology Data Exchange representatives, and International Nuclear Information System representatives from the following source:

Office of Scientific and Technical Information

PO Box 62

Oak Ridge, TN 37831

Telephone 865-576-8401

Fax 865-576-5728

E-mail reports@osti.gov

Website http://www.osti.gov/contact.html

This report was prepared as an account of work sponsored by an agency of the United States Government. Neither the United States Government nor any agency thereof, nor any of their employees, makes any warranty, express or implied, or assumes any legal liability or responsibility for the accuracy, completeness, or usefulness of any information, apparatus, product, or process disclosed, or represents that its use would not infringe privately owned rights. Reference herein to any specific commercial product, process, or service by trade name, trademark, manufacturer, or otherwise, does not necessarily constitute or imply its endorsement, recommendation, or favoring by the United States Government or any agency thereof. The views and opinions of authors expressed herein do not necessarily state or reflect those of the United States Government or any agency thereof. 
Reactor and Nuclear Systems Division

Assembly and Delivery of Rabbit Capsules for Irradiation of Silicon Carbide Cladding Tube Specimens in the High Flux Isotope Reactor

Christian M. Petrie

Takaaki Koyanagi

Date Published: September 6, 2017

NSUF Work Package \#: UF-17OR020711

Work Package Manager: Kory Linton

Milestone \#: M3UF-17OR0207112

Prepared by

OAK RIDGE NATIONAL LABORATORY

Oak Ridge, TN 37831-6283

managed by

UT-BATTELLE, LLC

for the

US DEPARTMENT OF ENERGY

under contract DE-AC05-00OR22725 



\section{CONTENTS}

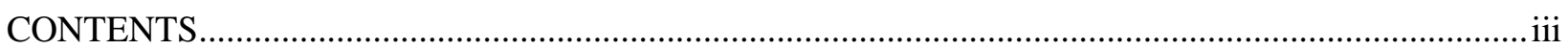

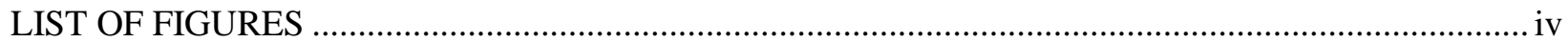

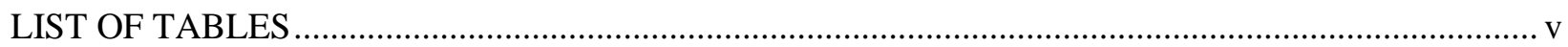

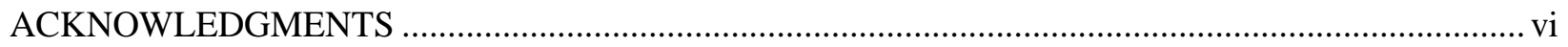

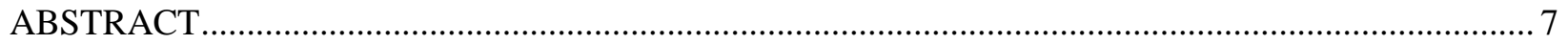

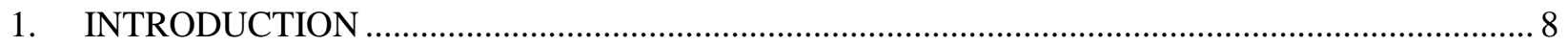

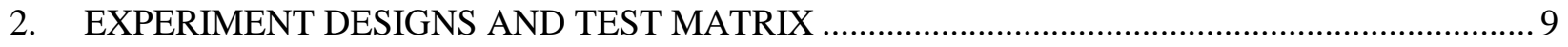

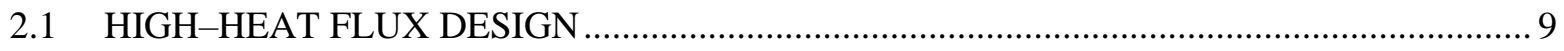

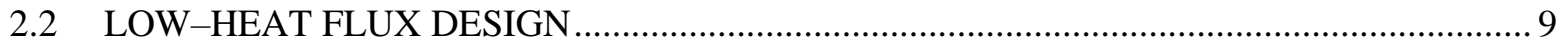

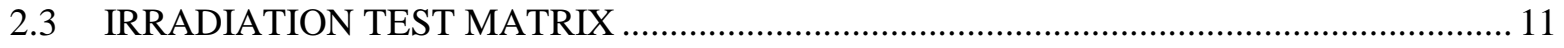

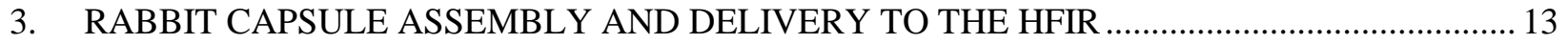

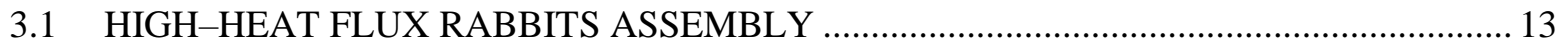

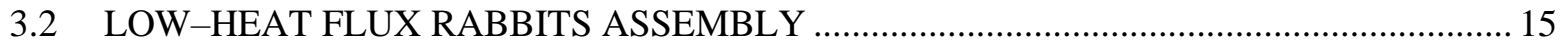

3.3 QUALITY ASSURANCE, FABRICATION PACKAGE, AND DELIVERY TO THE

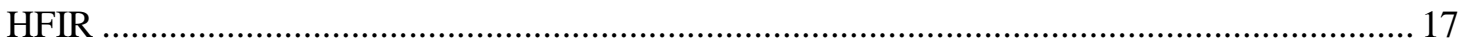

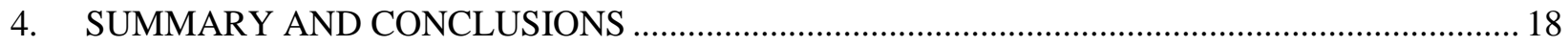

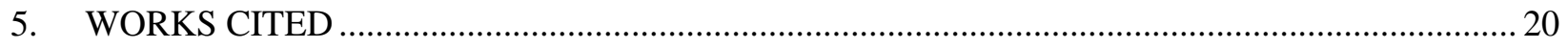

APPENDIX A. FABRICATION AND QUALITY ASSURANCE DOCUMENTATION FOR COMPLETED RABBITS. 


\section{LIST OF FIGURES}

Figure 1. Previously developed design concept for irradiating SiC cladding tubes under a high radial heat flux.

Figure 2. Section view showing low-heat flux design concept developed under the NSUF project. ........ 10

Figure 3. $\mathrm{SiC} / \mathrm{SiC}$ composite cladding specimen temperature $\left({ }^{\circ} \mathrm{C}\right)$ contours during irradiation in the high (left) and low (right) heat flux design configurations................................................. 11

Figure 4. Parts (left) and assembly (right) of rabbit ATFSC06. ….................................................... 13

Figure 5. Parts for assembly of rabbits ATFSC07 (left) and ATFSC09 (right)..................................... 14

Figure 6. Top-down view of CEA SiC/SiC composite specimen N1N3(8) assembled inside rabbit housing ATFSC06 with the heater, sleeve, foil, and thermometry surrounded by quartz wool.

Figure 7. Example of optical microscopy performed on each specimen (SA3-2 in this case) before irradiation.

Figure 8. Capsule parts for low-heat flux rabbits SCL01, SCL05, and SCL06.

Figure 9. Cladding specimens assembled with centering thimbles for the low-heat flux design configuration.

Figure 10. Example of optical microscopy performed on coated specimen 7-TM-TiN before irradiation in low-heat flux rabbit SCL06. 


\section{LIST OF TABLES}

Table 1. Rabbit irradiation test matrix showing the loading of specimens within each rabbit, the irradiation positions, and fill gases ...

Table 2. Specimen irradiation test matrix showing number of specimens to be irradiated according to specimen manufacturer, type, coating, and heat flux (high or low heat flux design). 


\section{ACKNOWLEDGMENTS}

This research was sponsored by the Nuclear Science User Facilities (NSUF) Program of the US Department of Energy (DOE), Office of Nuclear Energy. Neutron irradiation in the High Flux Isotope Reactor (HFIR) is made possible by the Office of Basic Energy Sciences, US DOE. The report was authored by UT-Battelle under Contract No. DE-AC05-00OR22725 with the DOE. The contributions of Kurt Terrani, ORNL program manager for the NSUF program, Kory Linton, the project manager for this work, and Yutai Katoh, the principal investigator for this work, are gratefully acknowledged. Caen Ang coordinated all coating of the cladding tube specimens. David Bryant performed most of the capsule assembly work and managed the welding and nondestructive examinations. Cladding specimens were provided by Christian Deck (General Atomics, San Diego, CA), Weon-Ju Kim (Korean Atomic Energy Research Institute, South Korea), and Cédric Sauder (Commissariat à l'Energie Atomique, France). 


\begin{abstract}
Neutron irradiation of silicon carbide ( $\mathrm{SiC}$ )-based fuel cladding under a high radial heat flux presents a critical challenge for SiC cladding concepts in light water reactors (LWRs). Fission heating in the fuel provides a high heat flux through the cladding, which, combined with the degraded thermal conductivity of $\mathrm{SiC}$ under irradiation, results in a large temperature gradient through the thickness of the cladding. The strong temperature dependence of swelling in $\mathrm{SiC}$ creates a complex stress profile in SiCbased cladding tubes as a result of differential swelling. The Nuclear Science User Facilities (NSUF) Program within the US Department of Energy Office of Nuclear Energy is supporting research efforts to improve the scientific understanding of the effects of irradiation on SiC cladding tubes. Ultimately, the results of this project will provide experimental validation of multi-physics models for SiC-based fuel cladding during LWR operation. The first objective of this project is to irradiate tube specimens using a previously developed design that allows for irradiation testing of miniature $\mathrm{SiC}$ tube specimens subjected to a high radial heat flux. The previous "rabbit" capsule design uses the gamma heating in the core of the High Flux Isotope Reactor (HFIR) to drive a high heat flux through the cladding tube specimens. A compressible aluminum foil allows for a constant thermal contact conductance between the cladding tubes and the rabbit housing despite swelling of the SiC tubes. To allow separation of the effects of irradiation from those due to differential swelling under a high heat flux, a new design was developed under the NSUF program. This design allows for irradiation of similar SiC cladding tube specimens without a high radial heat flux. This report briefly describes the irradiation experiment design concepts, summarizes the irradiation test matrix, and reports on the successful delivery of six rabbit capsules to the HFIR. Rabbits of both low and high heat flux configurations have been assembled, welded, evaluated, and delivered to the HFIR along with a complete quality assurance fabrication package. These rabbits contain a wide variety of specimens including monolith tubes, $\mathrm{SiC}$ fiber $\mathrm{SiC}$ matrix ( $\mathrm{SiC} / \mathrm{SiC}$ ) composites, duplex specimens (inner composite, outer monolith), and specimens with a variety of metallic or ceramic coatings on the outer surface. The rabbits are targeted for insertion during HFIR cycle 475, which is scheduled for September 2017.
\end{abstract}




\section{INTRODUCTION}

Silicon carbide $(\mathrm{SiC})$ is a candidate material for a variety of nuclear applications because of its high-temperature strength, oxidation resistance, and stability under irradiation [1-6]. Although SiC has been under consideration for various nuclear applications since the 1960s, the more recent focus has been on using $\mathrm{SiC}$ as a fuel cladding for light water reactors (LWRs) to increase the accident tolerance of the fuel [7-13]. One of the major technical feasibility issues for SiC-based cladding is whether the cladding can survive the evolving stress state over the lifetime of the fuel [14-16]. A large amount of heat is generated as a result of fission occurring in the fuel, and that heat passes through the cladding before ultimately being rejected to the reactor coolant. As the cladding thermal conductivity degrades under irradiation, the high heat flux passing through the cladding results in significant temperature gradients through the cladding thickness. Because of the strong temperature dependence of swelling in SiC, the radial temperature gradients result in differential swelling, which creates a complex stress state in the cladding. This stress, combined with internal pressurization due to gaseous fission product accumulation inside the fuel rod, could result in cracking and fission product release.

The Nuclear Science User Facilities (NSUF) Program within the US Department of Energy (DOE) Office of Nuclear Energy (DOE-NE) is funding Oak Ridge National Laboratory (ORNL) to experimentally investigate irradiation effects on the stress state in SiC cladding subjected to LWR conditions. The results obtained from this irradiation testing will provide experimental validation of thermomechanical models that are used to predict cladding performance during LWR operation. "Rabbit" capsules have been designed to allow miniature $\mathrm{SiC}$ tube specimens to be irradiated in the core of the High Flux Isotope Reactor (HFIR) at ORNL. Post-irradiation examination of the irradiated cladding tubes will include optical microscopy (to check for cracking), Raman temperature mapping, resonant ultrasound spectroscopy (for determining changes in elastic modulus), gas permeability measurements, and destructive c-ring testing (to determine residual stresses) [17]. This work summarizes the assembly and delivery of six rabbits containing a variety of SiC cladding tube specimens to the HFIR. The specimens include chemical vapor deposition (CVD) monolith tubes, $\mathrm{SiC}$ fiber $\mathrm{SiC}$ matrix $(\mathrm{SiC} / \mathrm{SiC})$ composite tubes, and duplex specimens (inner composite, outer monolith). In addition, some specimens were coated with a metallic or ceramic layer with the intention of improving hermeticity and/or hydrothermal corrosion resistance. Some of the rabbits that are to be irradiated use a previous design that allows for the cladding tubes to be tested under a representative high heat flux. Others use a new design developed under the NSUF program that allows for irradiation of tube specimens at representative LWR temperatures without a high heat flux so that the effects of differential swelling can be separated from other irradiation effects. This report provides a brief overview of the irradiation test matrix, the capsule design concepts, and the successful delivery of all irradiation capsules to the HFIR. 


\section{EXPERIMENT DESIGNS AND TEST MATRIX}

\subsection{HIGH-HEAT FLUX DESIGN}

The high-heat flux irradiation capsule designed previously is shown in Figure 1 [18]. This design places the specimens around a molybdenum heater (dense gamma absorbing cylinder) at the center of the rabbit housing. The heater generates significant gamma heating, which passes through the cladding tube, resulting in a heat flux of approximately $0.6 \mathrm{MW} / \mathrm{m}^{2}$ at the outer surface of the cladding. The outside of the specimen is surrounded by an aluminum sleeve, an embossed aluminum foil, and an aluminum housing, which is directly cooled by the reactor primary coolant. The embossed foil allows the specimen to swell under irradiation while maintaining good thermal contact between the sleeve and the housing. The sleeve prevents large circumferential temperature variations on the outer surface of the cladding due to the periodic contact that would otherwise exist between the cladding and the foil. The cladding surface was estimated to be $300-350^{\circ} \mathrm{C}$, based on finite element analysis (FEA) [18]. The FEA results were validated using passive $\mathrm{SiC}$ temperature monitors located inside the molybdenum heaters.

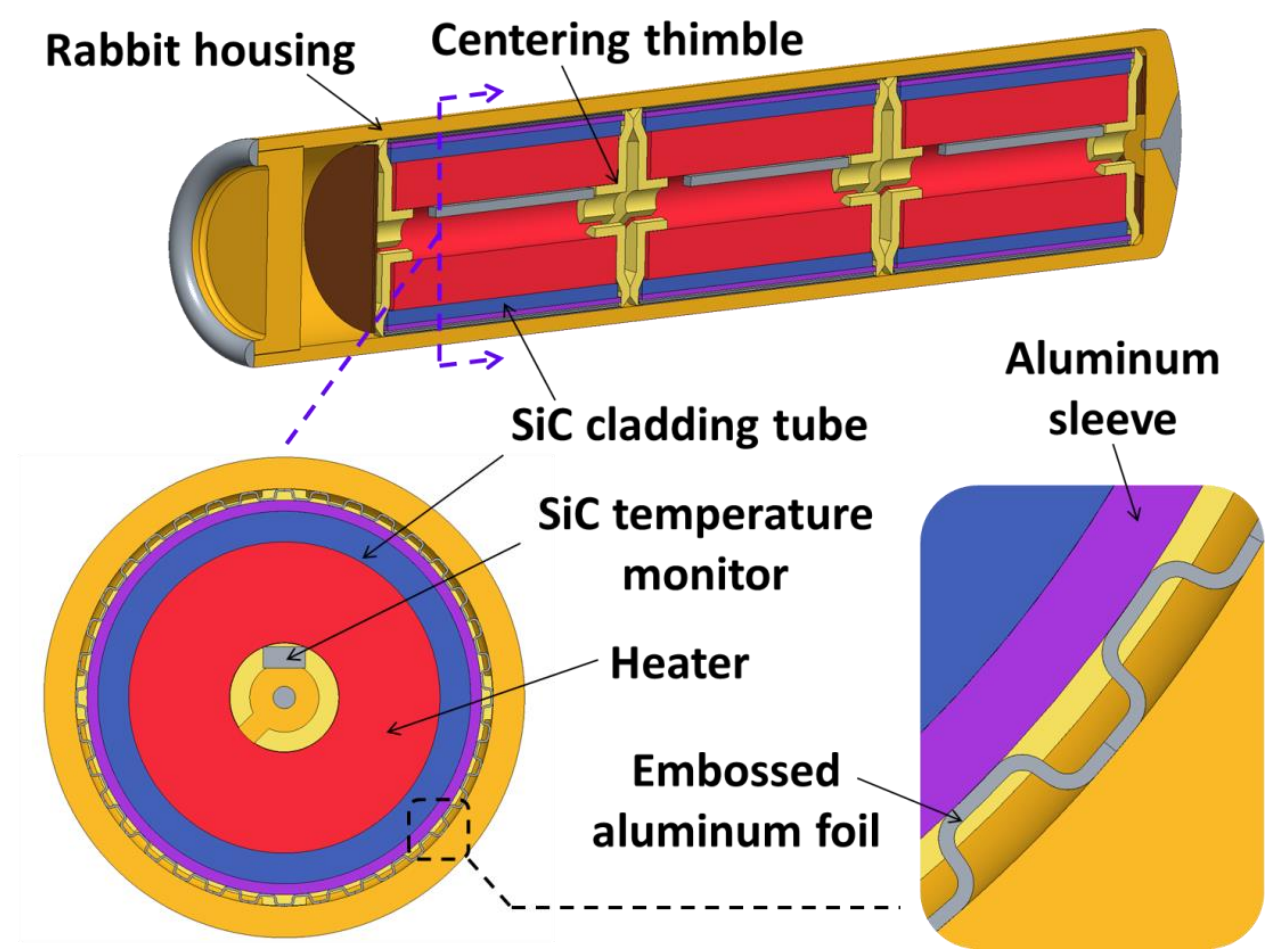

Figure 1. Previously developed design concept for irradiating $\mathrm{SiC}$ cladding tubes under a high radial heat flux.

\subsection{LOW-HEAT FLUX DESIGN}

As mentioned previously, the low-heat flux design was developed under the NSUF program to provide $\mathrm{SiC}$ cladding tube specimens that have been irradiated without differential swelling stresses resulting from the high radial heat flux and associated temperature gradients [19]. This allows for the separation of differential swelling effects from effects related to radiation damage. Figure 2 shows the concept for the low $\left(\sim 0.08 \mathrm{MW} / \mathrm{m}^{2}\right)$ heat flux design. Three cladding tubes are stacked in the vertical direction inside the rabbit housing. Each tube specimen has centering thimbles inserted on either end to 
keep the specimens centered within the housing. A compression spring is placed at the top of the rabbit to prevent the centering thimbles from dislodging from the cladding specimens. All centering thimbles are made of aluminum, except for the bottom thimble, which is made of a titanium alloy. The low density and high thermal conductivity of aluminum minimizes temperature extremes on the ends of the specimens due to increased gamma heating in the thimbles. To further reduce axial temperature gradients along the length of the specimens, graphite inserts are placed inside the cladding between the two centering thimbles to provide a more uniform heat loading along the length of the cladding tubes. The bottom thimble is made of titanium because of its low thermal conductivity, which reduces axial heat losses from the bottom cladding specimen to the cool bottom surface of the capsule housing. Figure 3 shows predicted temperatures for a $\mathrm{SiC} / \mathrm{SiC}$ composite specimen during irradiation in both the high- and low-heat flux design configurations. Temperatures for the high-heat flux configuration were replotted from the data in Petrie et al. [18]. Clearly the low-heat flux design allows for much lower temperature gradients within the specimens.

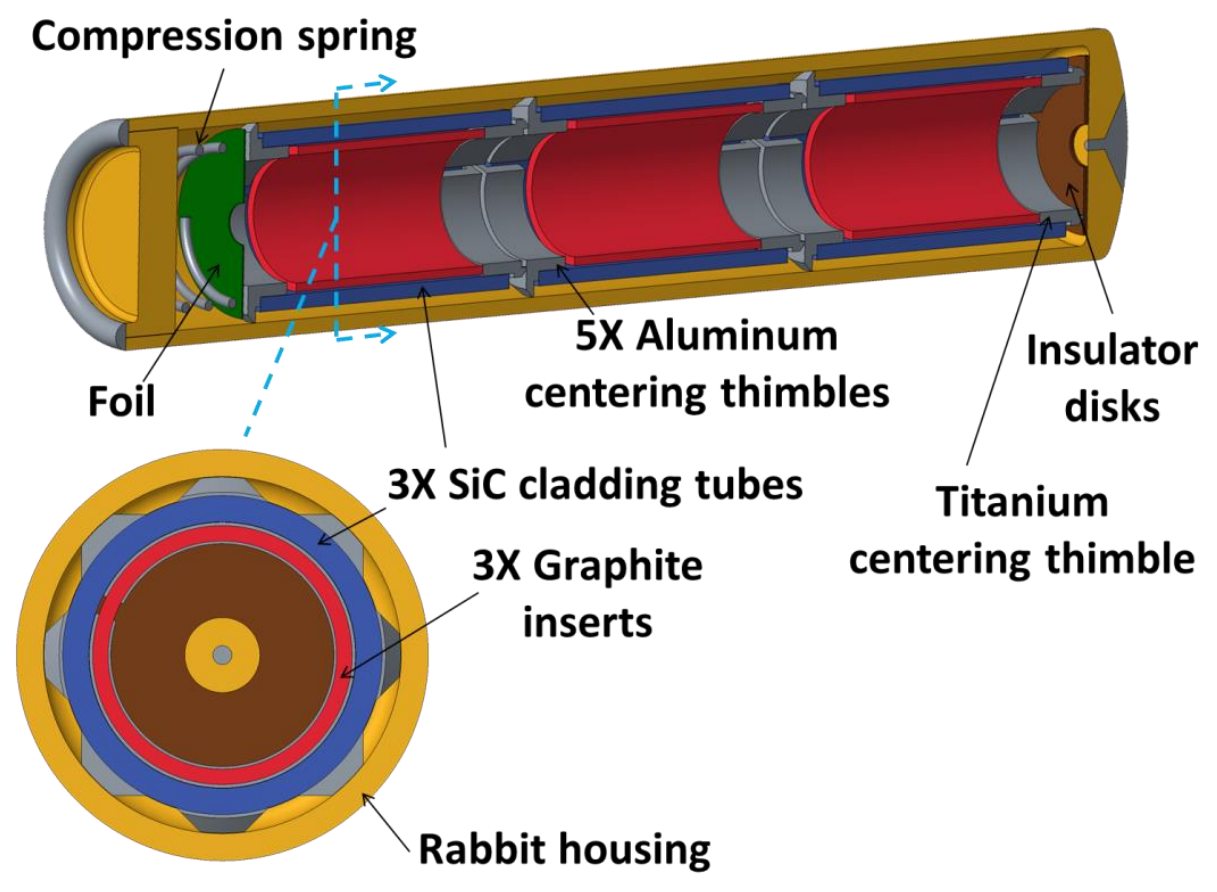

Figure 2. Section view showing low-heat flux design concept developed under the NSUF project. 

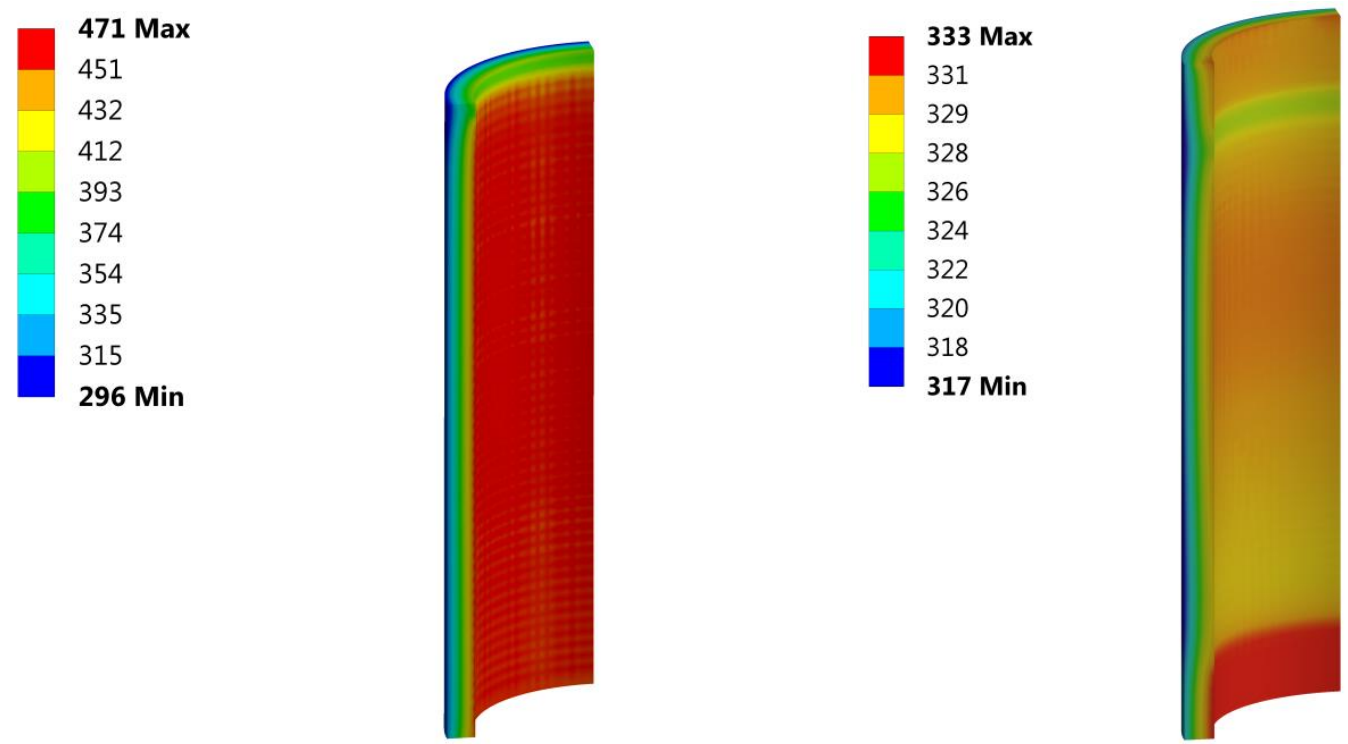

Figure 3. $\mathrm{SiC} / \mathrm{SiC}$ composite cladding specimen temperature $\left({ }^{\circ} \mathrm{C}\right)$ contours during irradiation in the high (left) and low (right) heat flux design configurations.

\subsection{IRRADIATION TEST MATRIX}

Table 1 and Table 2 summarize the irradiation test matrix. The specimens come from a variety of manufacturers, including The Dow Chemical Company (Dow), General Atomics (GA), the Korean Atomic Energy Research Institute (KAERI) in South Korea, and the Commissariat à l'Energie Atomique (CEA) in France. Coating was performed by two companies: Richter Precision Inc. (RP) and Techmetals Inc. (TM). Coatings included $\mathrm{Cr}, \mathrm{CrN}$, and TiN. Table 1 shows the loading of specimens in each rabbit along with the irradiation positions and fill gases. Each rabbit contains three specimens. Table 2 summarizes all specimens by specimen manufacturer, type, coating, and heat flux (high- or low-heat flux design). All specimens will be irradiated for one cycle (cycle 475) in the HFIR, which will result in a radiation dose of approximately $2.3 \mathrm{dpa}$ [18]. The targeted cladding surface temperature is approximately $300-350^{\circ} \mathrm{C}$ for all rabbits. Temperature gradients through the thickness depend on the heat flux and the specimen thermal conductivity, which varies with specimen type and neutron fluence. The nominal specimen dimensions are $8.5 \mathrm{~mm}$ outer diameter, $7.1 \mathrm{~mm}$ inner diameter, and $16 \mathrm{~mm}$ length.

Table 1. Rabbit irradiation test matrix showing the loading of specimens within each rabbit, the irradiation positions, and fill gases

\begin{tabular}{ccccccc}
\hline Rabbit & Heat flux & Cladding 1 & Cladding 2 & Cladding 3 & $\begin{array}{c}\text { Irradiation } \\
\text { position }\end{array}$ & Fill gas \\
\hline ATFSC06 & High & CVD-E & GA-TGI-C-1 & N1N3(8) & G4-4 & $\mathrm{He}$ \\
ATFSC07 & High & CVD-H & TYPE S-1 & SA3-2 & A1-4 & $\mathrm{He}$ \\
ATFSC09 & High & CVD-G & 1-TM-CrN & 4-RP-CrN & A4-4 & $\mathrm{He}$ \\
SCL01 & Low & CVD-L & SA3-1 & N1N3(1) & A1-5 & $85 \%$ He, Ar bal. \\
SCL05 & Low & CVD-Q & 6-RP-Cr & 2-TM-CrN & D1-5 & $85 \% \mathrm{He}$ Ar bal. \\
SCL06 & Low & CVD-R & 3-RP-CrN & 7-TM-TiN & G7-4 & $85 \%$ He, Ar bal. \\
\hline
\end{tabular}


Table 2. Specimen irradiation test matrix showing number of specimens to be irradiated according to specimen manufacturer, type, coating, and heat flux (high or low heat flux design).

\begin{tabular}{llllcc}
\hline \multirow{2}{*}{ Manufacturer } & \multicolumn{1}{c}{ Type } & Coating & \multicolumn{1}{c}{ Specimen ID } & \multicolumn{1}{c}{ Heat flux } \\
How & Monolith & None & CVD-X (X=E, G, H, L, Q, R) & 3 & 3 \\
GA & SiC/SiC composite & None & GA-TGI-C-1 & 1 & 0 \\
GA & $\begin{array}{l}\text { Duplex: inner composite, outer } \\
\text { monolith }\end{array}$ & CrN & 1-TM-CrN, 3-RP-CrN & 1 & 1 \\
& Duplex: inner composite, outer & & & & \\
GA & Cr & 6-RP-Cr & 0 & 1 \\
& monolith & & & & \\
KAERI & Duplex: inner composite, outer & None & TYPE S-1, SA3-1, SA3-2 & 2 & 1 \\
CEA & monolith & None & N1N3(1), N1N3(8) & 1 & 1 \\
CEA & SiC/SiC composite & CrN & 2-TM-CrN, 4-RP-CrN & 1 & 1 \\
CEA & SiC/SiC composite & TiN & 7-TM-TiN & 0 & 1 \\
\hline
\end{tabular}




\section{RABBIT CAPSULE ASSEMBLY AND DELIVERY TO THE HFIR}

\subsection{HIGH-HEAT FLUX RABBITS ASSEMBLY}

The three high-heat flux rabbits (ATFSC06, ATFSC07, and ATFSC09) were assembled. Pictures of the parts layout and specimen sub-assemblies for rabbit ATFSC06 are shown in Figure 4. Figure 5 shows the parts layout for rabbits ATFSC07 and ATFSC09. Figure 6 shows a top-down view of CEA $\mathrm{SiC} / \mathrm{SiC}$ composite specimen N1N3(8) assembled inside the rabbit housing ATFSC06 with the heater, sleeve, foil, and thermometry surrounded by quartz wool. The signed capsule fabrication request forms are provided in APPENDIX A. Figure 7 shows an example of the pre-irradiation optical microscopy that is performed on each specimen (SA3-2 in this case) so that defects that exist in the specimen before irradiation are not attributed to radiation damage. The top of the specimen shows engraving marks for identifying the specimen. A surface defect is clearly visible in the bottom right picture.
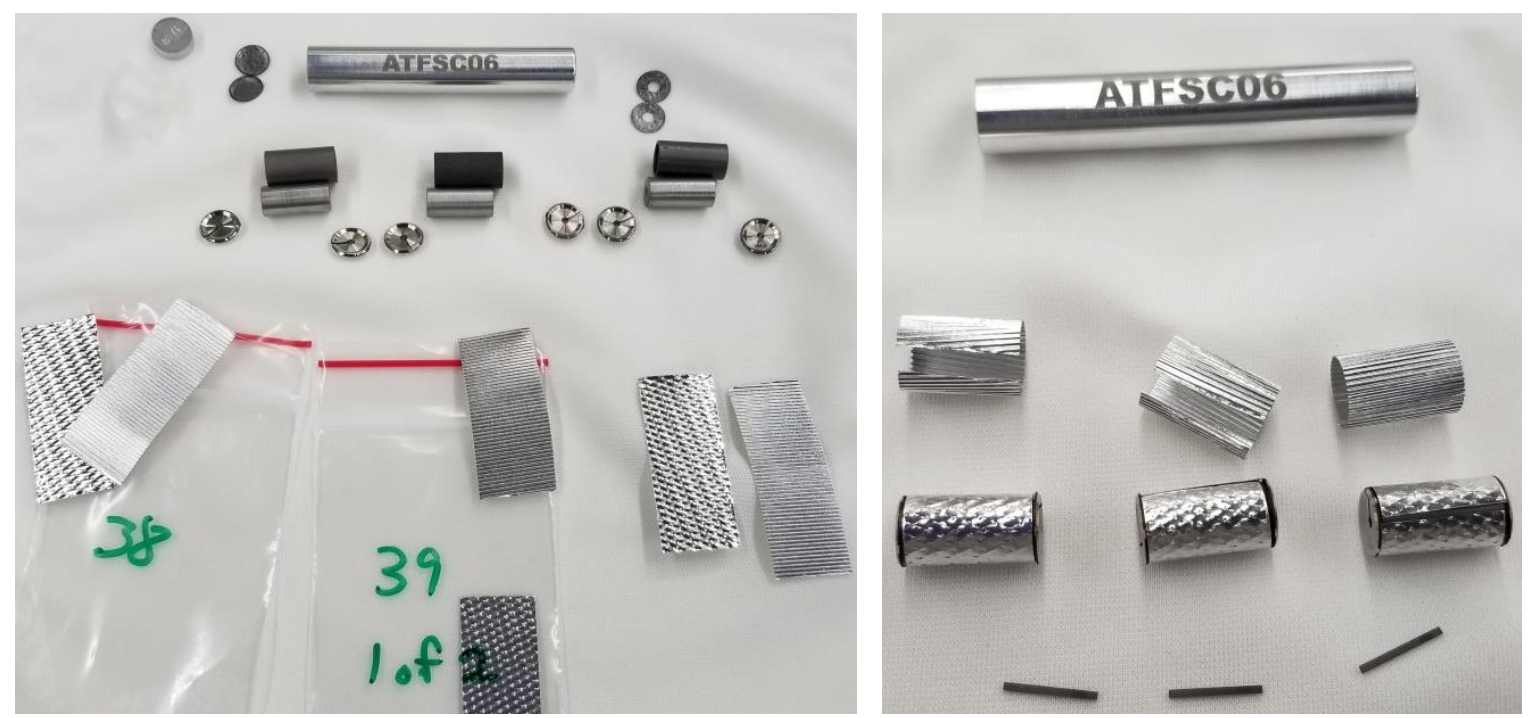

Figure 4. Parts (left) and assembly (right) of rabbit ATFSC06. 

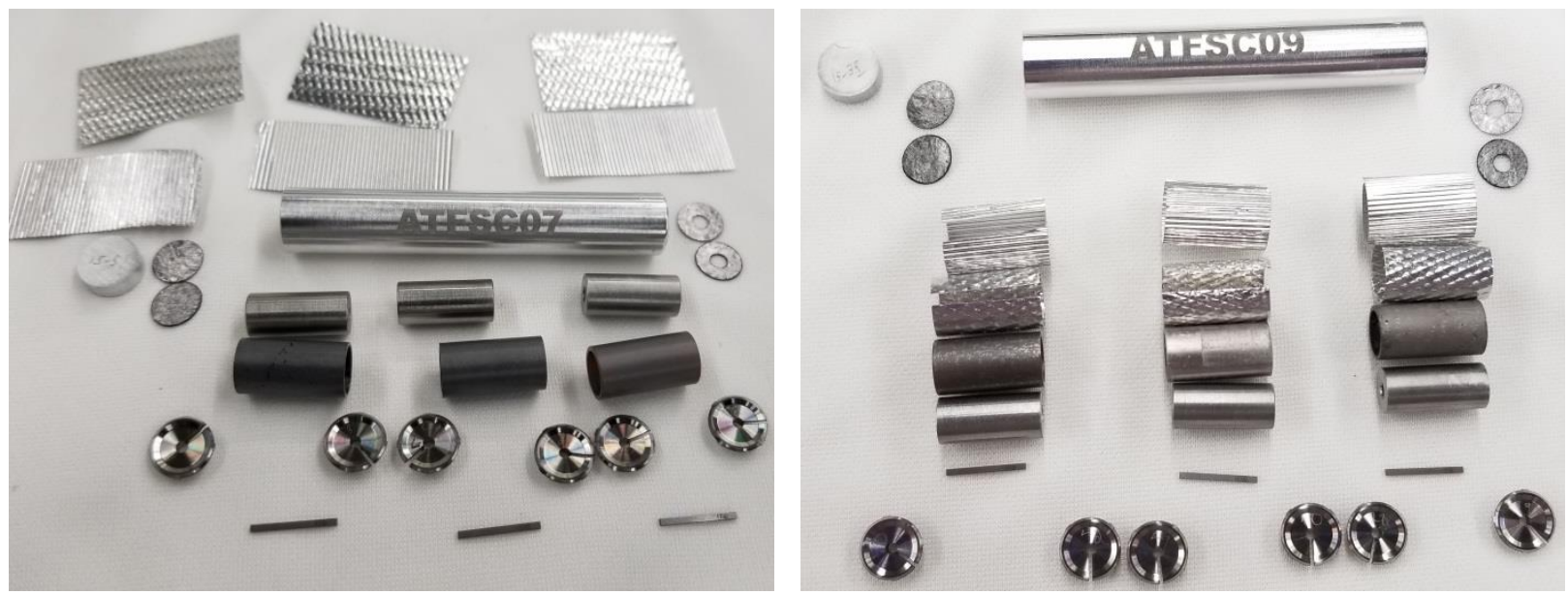

Figure 5. Parts for assembly of rabbits ATFSC07 (left) and ATFSC09 (right).

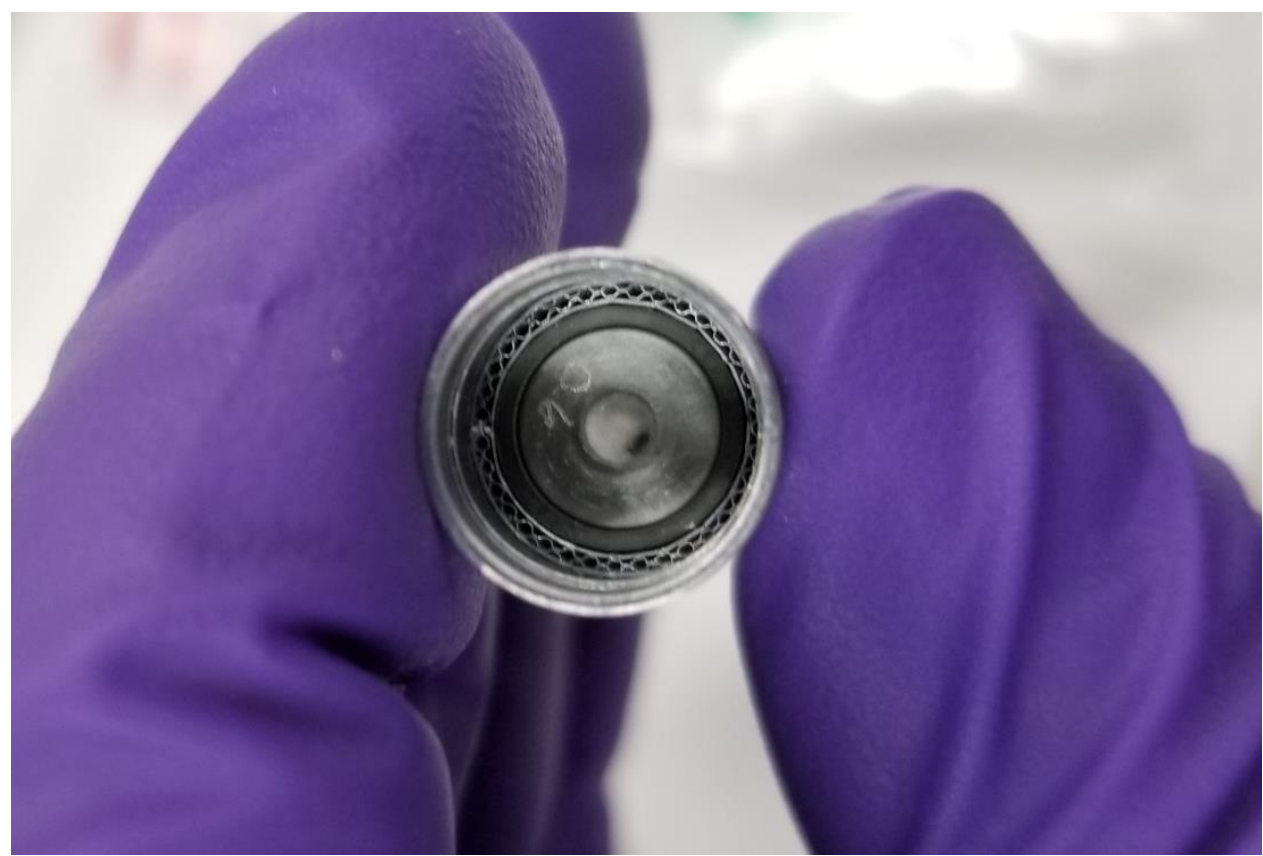

Figure 6. Top-down view of $\mathrm{CEA} \mathrm{SiC/SiC} \mathrm{composite} \mathrm{specimen} \mathrm{N1N3(8)} \mathrm{assembled} \mathrm{inside} \mathrm{rabbit}$ housing ATFSC06 with the heater, sleeve, foil, and thermometry surrounded by quartz wool. 

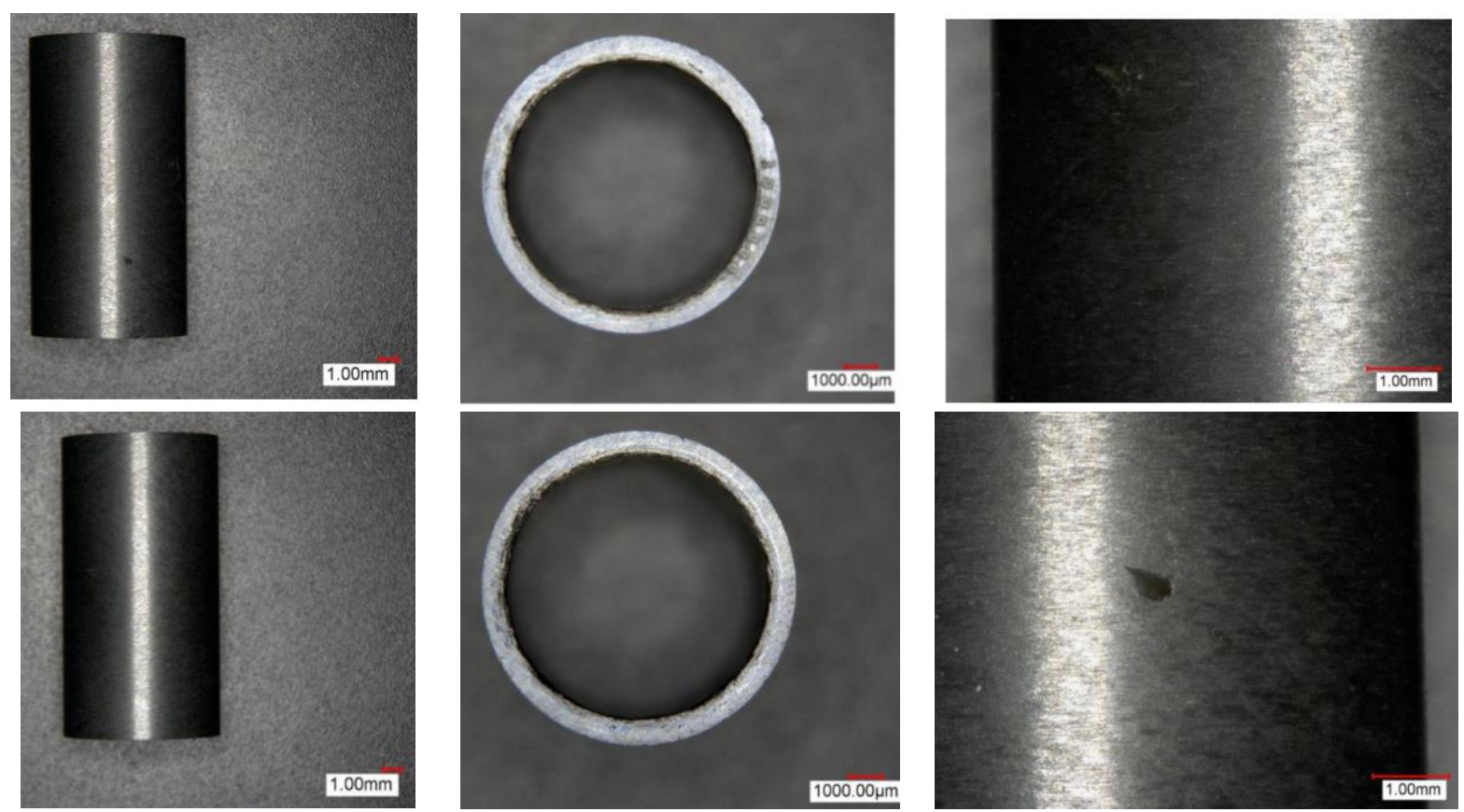

Figure 7. Example of optical microscopy performed on each specimen (SA3-2 in this case) before irradiation.

All capsule components were dimensionally inspected and cleaned according to HFIR-approved procedures, drawings, and sketches. After assembly of the internal components, all rabbit housing end caps were welded to the housings using an electron beam weld. The capsules were then placed inside sealed chambers that were evacuated and backfilled with ultra-high-purity helium gas three times to ensure a pure helium environment. The chambers were placed inside a glove box, which was also evacuated and backfilled with helium. Each rabbit had a small hole in the bottom of the housing that was sealed using a gas tungsten arc welding procedure. All welds passed visual examination. Each capsule was then sent for nondestructive examination, which included a helium leak test, hydrostatic compression at a pressure of 1,035 psi, mass comparisons before and after hydrostatic compression to ensure no water penetrated the capsule housing, and a final post-compression helium leak test. All rabbits passed helium leak testing and hydrostatic compression.

\subsection{LOW-HEAT FLUX RABBITS ASSEMBLY}

Three low-heat flux rabbits (SCL01, SCL05, and SCL06) were assembled. Pictures of the layout for each rabbit before irradiation are shown for these three rabbits in Figure 8. Figure 9 shows an example of cladding specimens assembled with centering thimbles. Figure 10 shows an example of optical microscopy performed on a coated specimen (7-TM-TiN) that was included in low-heat flux irradiation capsule SCL06. The low-heat flux rabbits and rabbit components were inspected, cleaned, assembled, and tested using the same processes and procedures as the high-heat flux rabbits, except that the backfill gas was an $85 \% \mathrm{He}-\mathrm{Ar}$ balance mixture instead of pure helium. All rabbits passed weld examination, helium leak testing, and hydrostatic compression. 

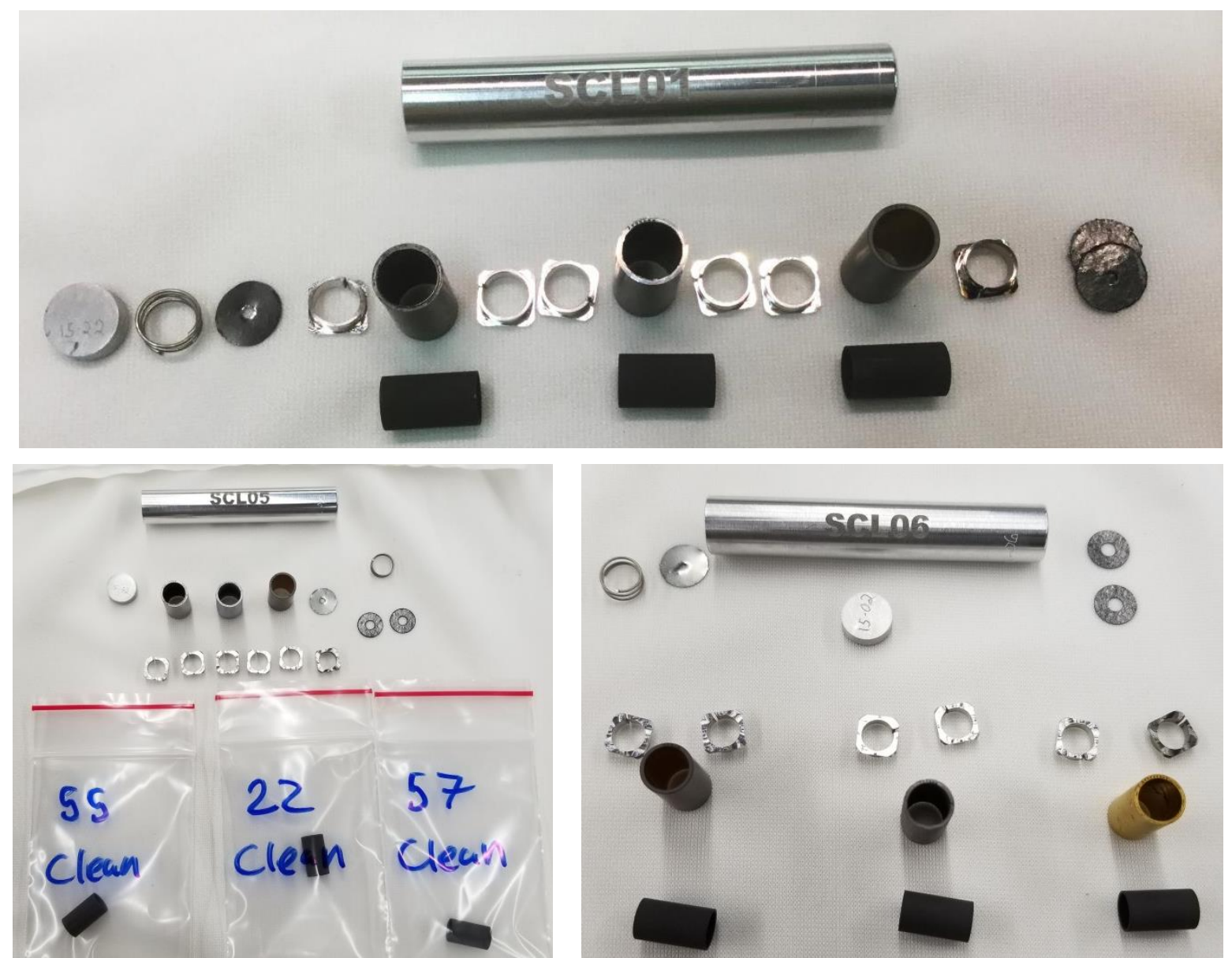

Figure 8. Capsule parts for low-heat flux rabbits SCL01, SCL05, and SCL06.

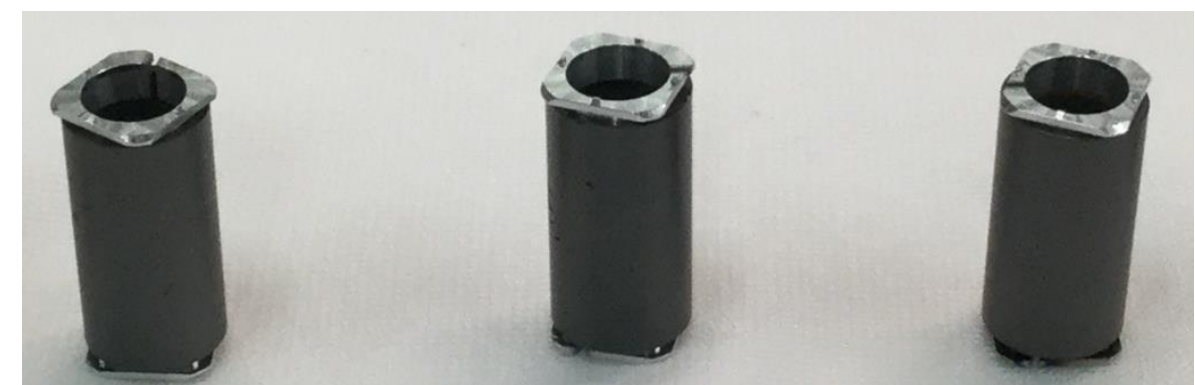

Figure 9. Cladding specimens assembled with centering thimbles for the low-heat flux design configuration. 

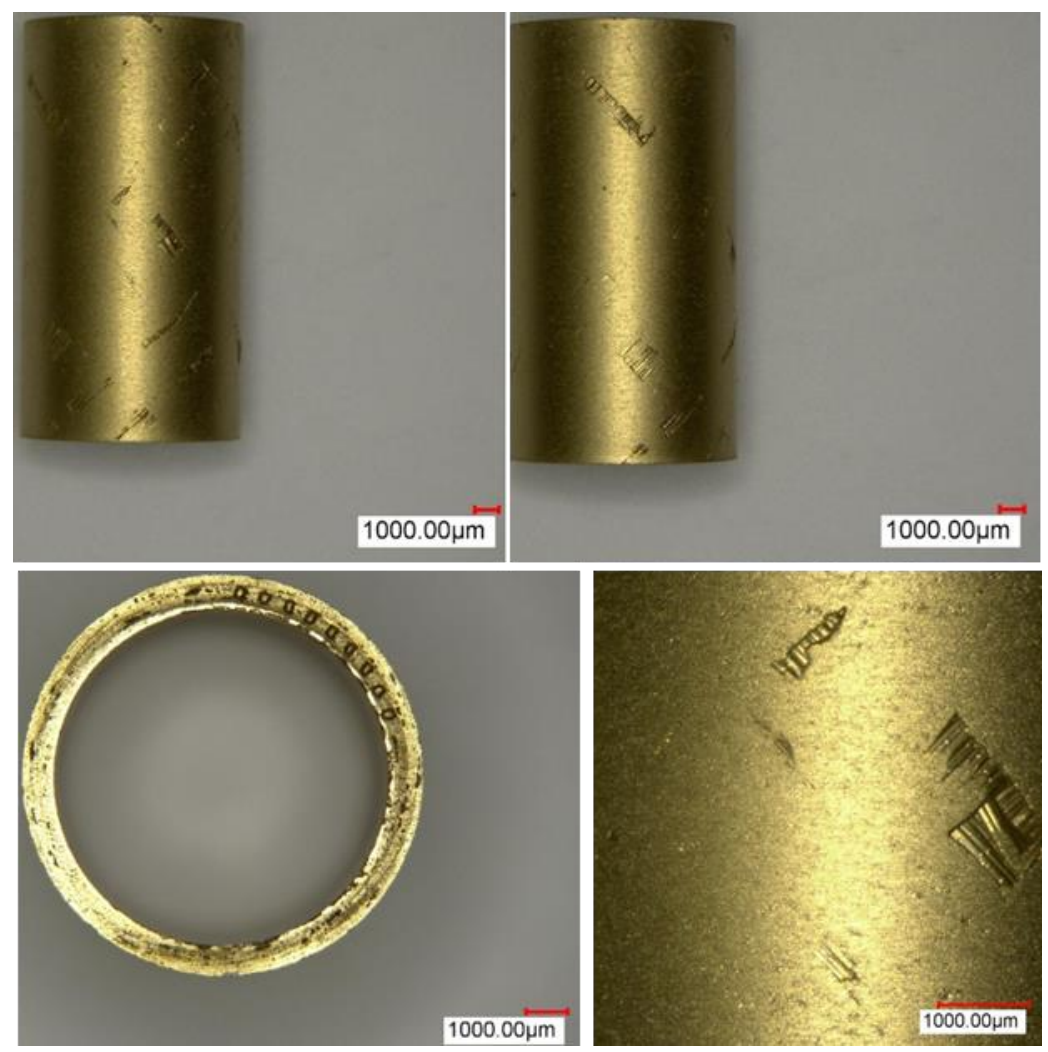

Figure 10. Example of optical microscopy performed on coated specimen 7-TM-TiN before irradiation in low-heat flux rabbit SCLO6.

\subsection{QUALITY ASSURANCE, FABRICATION PACKAGE, AND DELIVERY TO THE HFIR}

Each rabbit irradiation experiment requires a fabrication package that is reviewed by an independent design engineer, a lead quality assurance (QA) representative, and a HFIR QA representative before acceptance for insertion into the HFIR. The fabrication package must satisfy the requirements of the Experiment Authorization Basis Document (EABD). Rabbit capsules fall under document EABDHFIR-2009-004. This document specifies a number of requirements that the rabbits must satisfy in the areas of

- thermal safety analyses,

- material certification,

- dimensional inspection,

- cleaning,

- assembly procedure,

- sample loading,

- fill gas,

- welding, and

- nondestructive evaluation.

A separate fabrication package was prepared for the low- and high-heat flux rabbit capsules. These packages were reviewed and approved by an independent design engineer, lead QA representative, and HFIR QA representative and accepted by HFIR on August 14, 2017. The final signed acceptance page of the EABD is provided in APPENDIX A. All six rabbits are scheduled for insertion during HFIR cycle 475 (September 2017). 


\section{SUMMARY AND CONCLUSIONS}

This work summarizes the capsule design concepts and the irradiation test matrix for six rabbit capsules, which were successfully assembled and delivered to the HFIR for insertion during cycle 475 (September 2017). Each rabbit contains three SiC cladding tube specimens, which will be evaluated postirradiation as part of an NSUF-funded project investigating the effects of irradiation with a high radial heat flux on the stress state in SiC-based fuel cladding. Three rabbits use a previous design that provides the required radial heat flux through the specimens during irradiation. A new design was developed under the NSUF program to allow for irradiation at LWR temperatures without a significant radial heat flux to allow the separation of effects related to differential swelling from other irradiation effects. A wide variety of specimens were included in the test matrix, including monolith tubes, $\mathrm{SiC} / \mathrm{SiC}$ composites, duplex specimens (inner composite, outer monolith), and specimens with a variety of metallic or ceramic coatings on the outer surfaces. The rabbits were successfully assembled, welded, evaluated, and delivered to the HFIR along with a complete QA fabrication package. Pictures of the rabbit assembly process and optical microscopy of select specimens are included in this report. Documentation of the capsule fabrication and final acceptance by HFIR is provided in an appendix. Ultimately, the results of this project will provide experimental validation of multi-physics models of the stress state of SiC-based fuel cladding during LWR operation. 



\section{WORKS CITED}

1. Snead, L.L., et al., "Silicon carbide composites as fusion power reactor structural materials," Journal of Nuclear Materials, 417 (2011) p. 330-339.

2. Giancarli, L., et al., "Progress in blanket designs using SiCf/SiC composites," Fusion Engineering and Design, 61-62 (2002) p. 307-318.

3. Katoh, Y., et al., "Radiation effects in $\mathrm{SiC}$ for nuclear structural applications," Current Opinion in Solid State and Materials Science, 16 (2012) p. 143-152.

4. Katoh, Y., et al., "Current status and recent research achievements in SiC/SiC composites," Journal of Nuclear Materials, 455 (2014) p. 387-397.

5. Katoh, Y., et al., "Continuous SiC fiber, CVI SiC matrix composites for nuclear applications: Properties and irradiation effects," Journal of Nuclear Materials, 448 (2014) p. 448-476.

6. Koyanagi, T., et al., "Effects of neutron irradiation on mechanical properties of silicon carbide composites fabricated by nano-infiltration and transient eutectic-phase process," Journal of Nuclear Materials, 448 (2014) p. 478-486.

7. Yueh, K. and K.A. Terrani, "Silicon carbide composite for light water reactor fuel assembly applications," Journal of Nuclear Materials, 448 (2014) p. 380-388.

8. Carpenter, D.M., An assessment of silicon carbide as a cladding material for light water reactors, in Nuclear Science and Engineering. 2011, Massachusetts Institute of Technology: Cambridge, MA.

9. Terrani, K.A., et al., "Silicon Carbide Oxidation in Steam up to $2 \mathrm{MPa}$," Journal of the American Ceramic Society, 97 (2014) p. 2331-2352.

10. Lee, Y., et al., "Safety Assessment of SiC Cladding Oxidation under Loss-of-Coolant Accident Conditions in Light Water Reactors," Nuclear Technology, 183 (2013) p. 210-227.

11. Katoh, Y. and K.A. Terrani, Systematic Technology Evaluation Program for SiC/SiC Compositebased Accident-Tolerant LWR Fuel Cladding and Core Structures: Revision 2015, Oak Ridge National Laboratory: Oak Ridge, TN (2015).

12. Barrett, K.E., et al., "Engineering Challenges of LWR Advanced Fuel Cladding Technology in Preparation for In-Reactor Demonstrations," in Transactions of the American Nuclear Society. 2012: p. 886-889.

13. Koyanagi, T. and Y. Katoh, "Mechanical properties of SiC composites neutron irradiated under light water reactor relevant temperature and dose conditions," Journal of Nuclear Materials, 494 (2017) p. 46-54.

14. Ben-Belgacem, M., et al., "Thermo-mechanical analysis of LWR SiC/SiC composite cladding," Journal of Nuclear Materials, 447 (2014) p. 125-142.

15. Stone, J.G., et al., "Stress analysis and probabilistic assessment of multi-layer SiC-based accident tolerant nuclear fuel cladding," Journal of Nuclear Materials, 466 (2015) p. 682-697.

16. Lee, Y. and M.S. Kazimi, "A structural model for multi-layered ceramic cylinders and its application to silicon carbide cladding of light water reactor fuel," Journal of Nuclear Materials, 458 (2015) p. 87-105.

17. Koyanagi, T., et al., "Post Irradiation Examination of SiC Tube Subjected to Simultaneous Irradiation and Radial High Heat Flux," in Transactions of the American Nuclear Society. 2017: San Francisco, CA. p. 386-388.

18. Petrie, C.M., et al., "Experimental design and analysis for irradiation of SiC/SiC composite tubes under a prototypic high heat flux," Journal of Nuclear Materials, 491 (2017) p. 94-104.

19. Petrie, C.M., K.A. Terrani, and Y. Katoh, "Accident Tolerant Fuel Cladding Tube Irradiations in the HFIR," in Transactions of the American Nuclear Society. 2017: San Francisco, CA. p. 413416. 



\section{APPENDIX A. FABRICATION AND QUALITY ASSURANCE DOCUMENTATION FOR COMPLETED RABBITS}





\section{APPENDIX A. FABRICATION AND QUALITY ASSURANCE DOCUMENTATION FOR COMPLETED RABBITS}

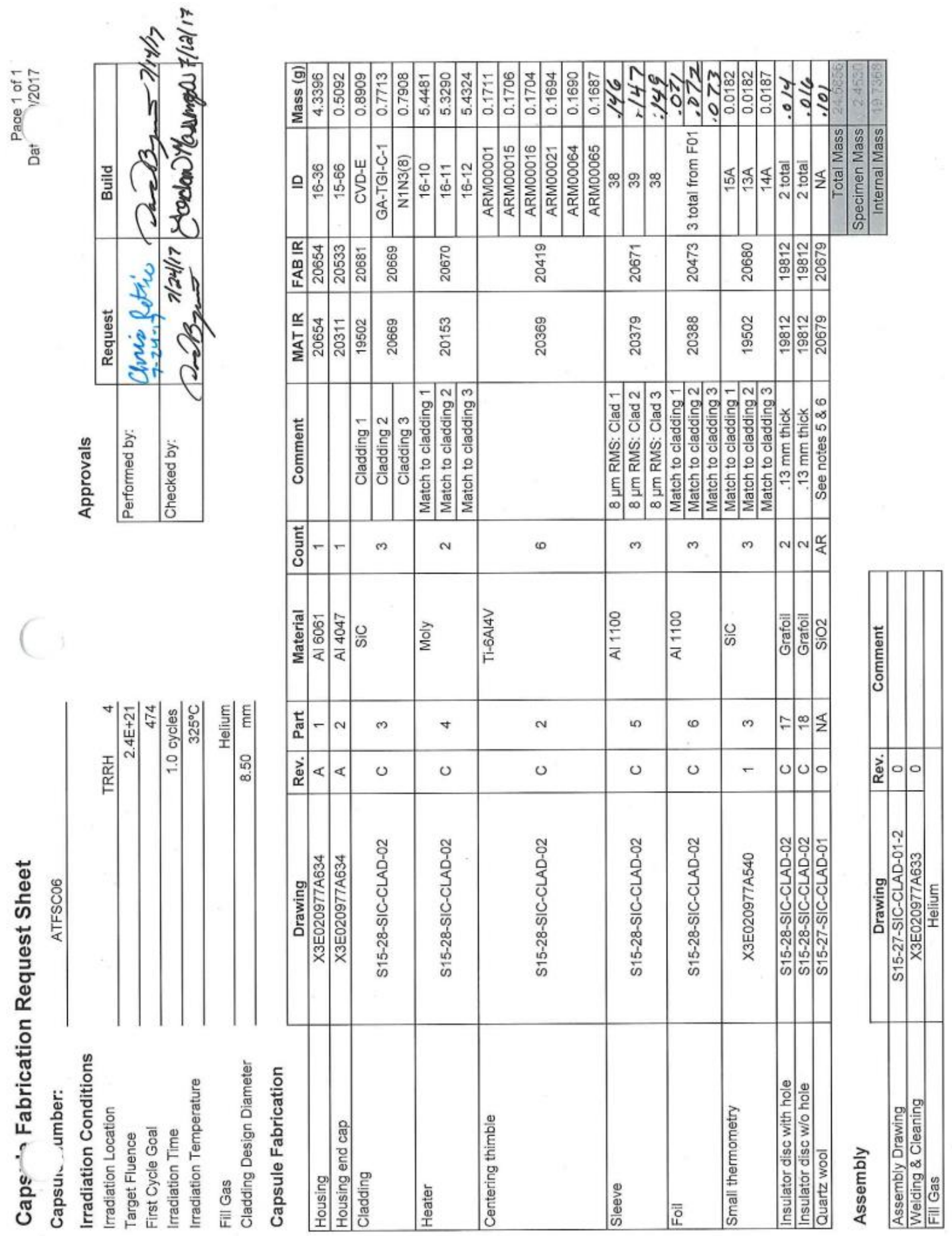




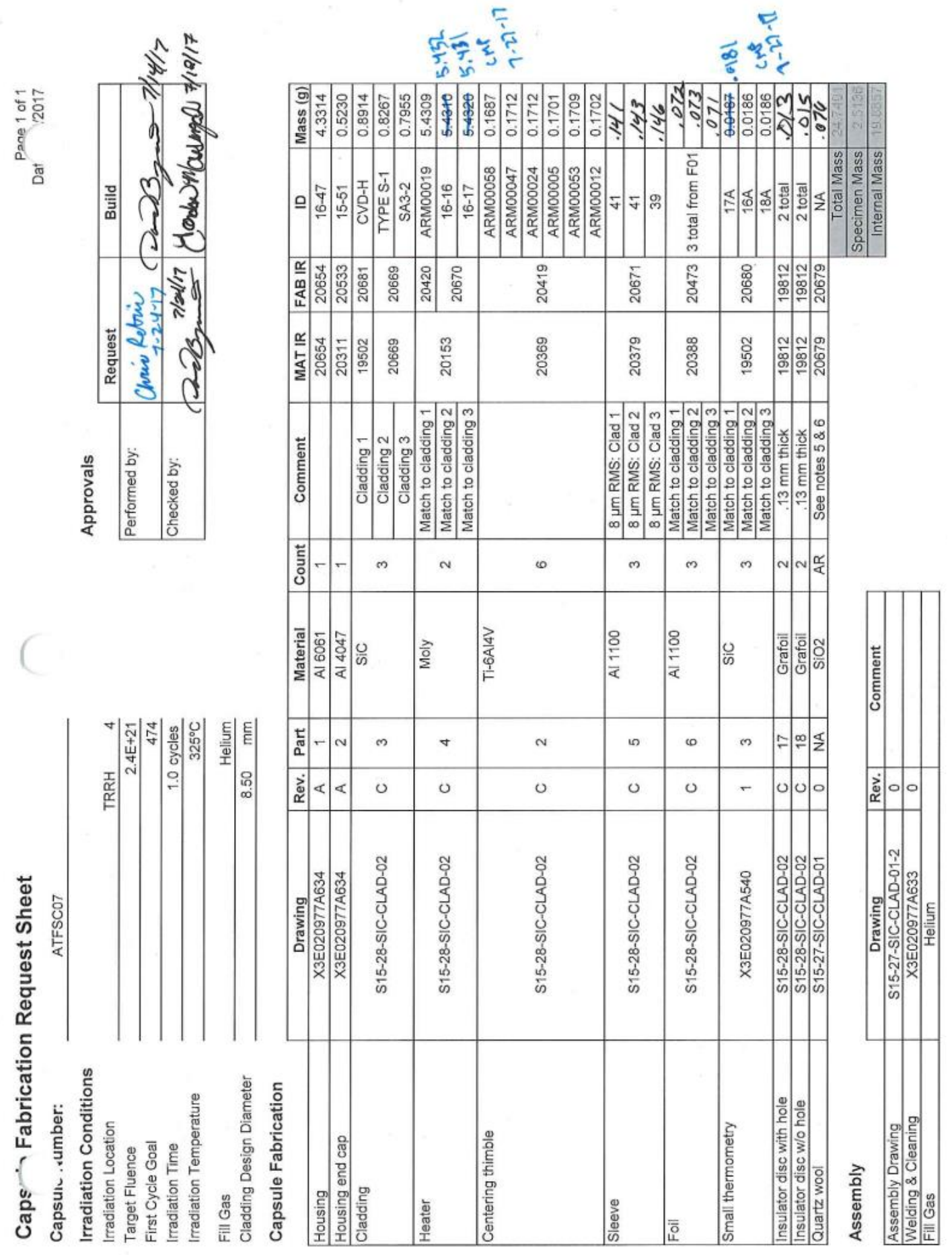




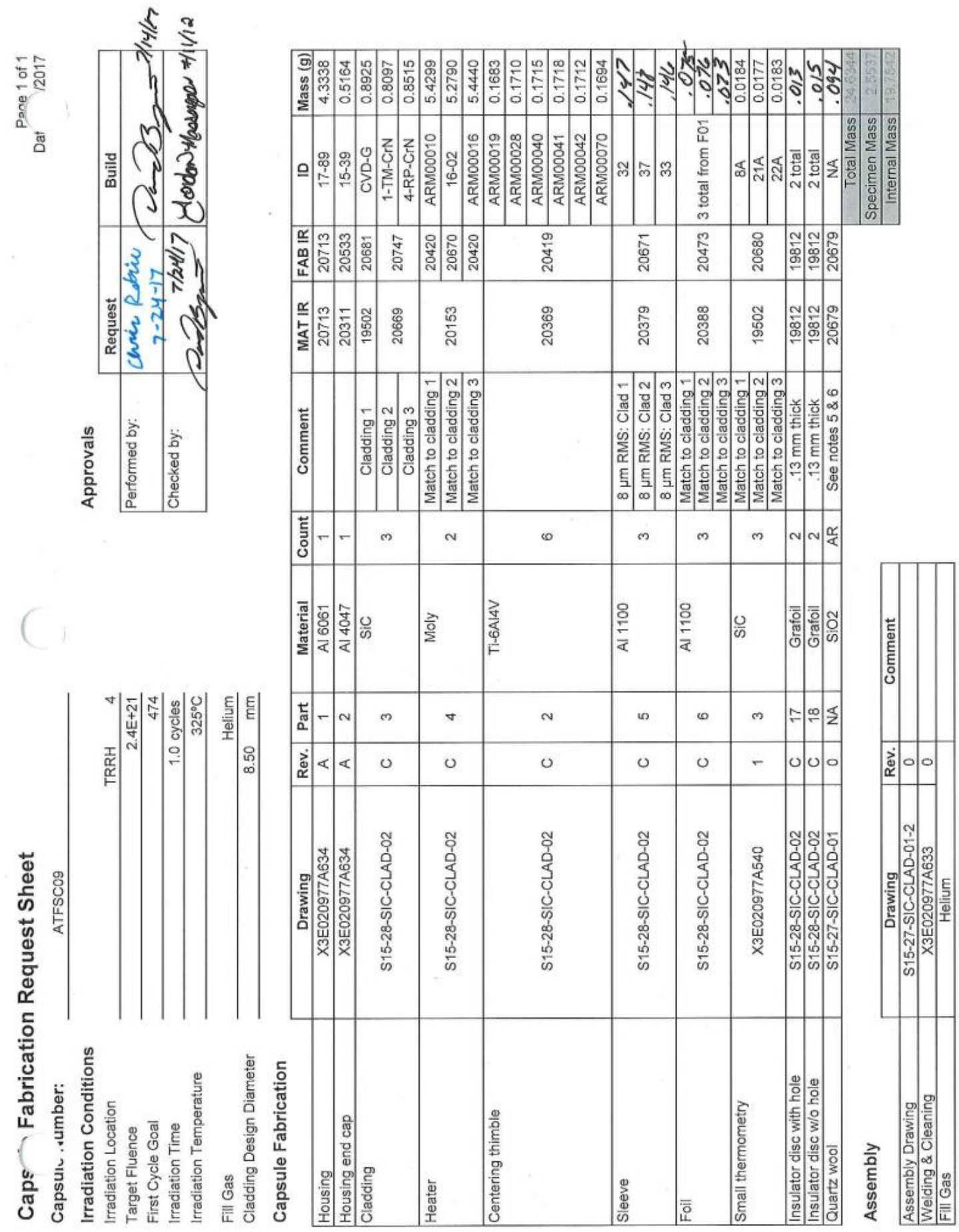


돌
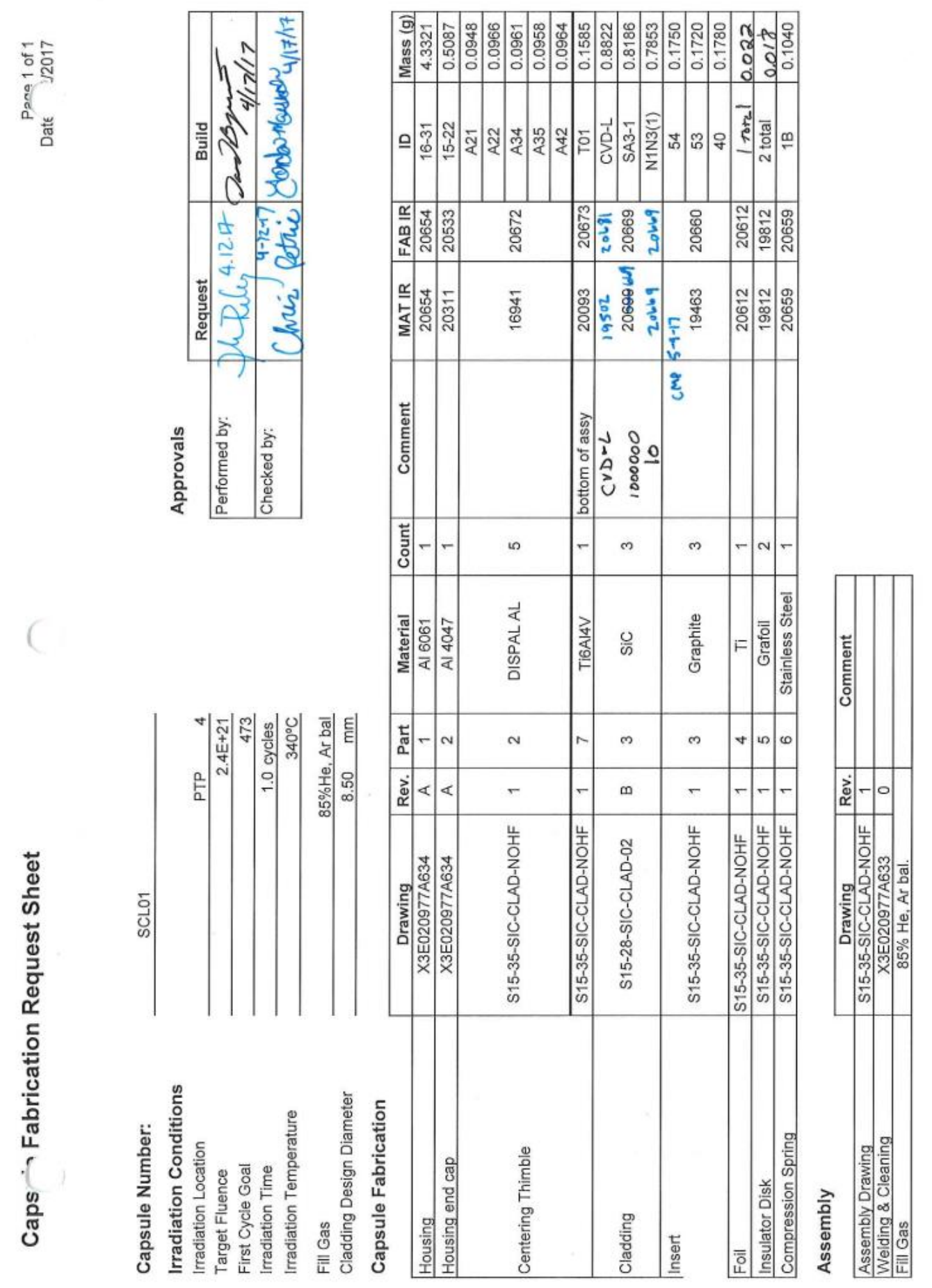
ल्लें⿰彳
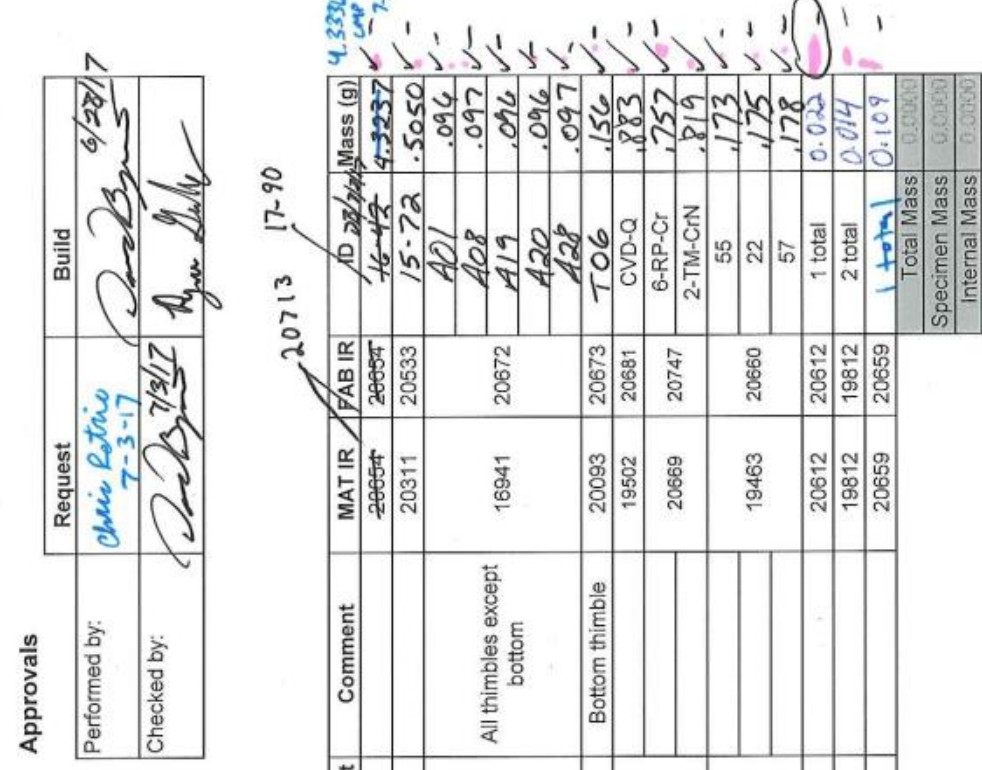

$m$ e
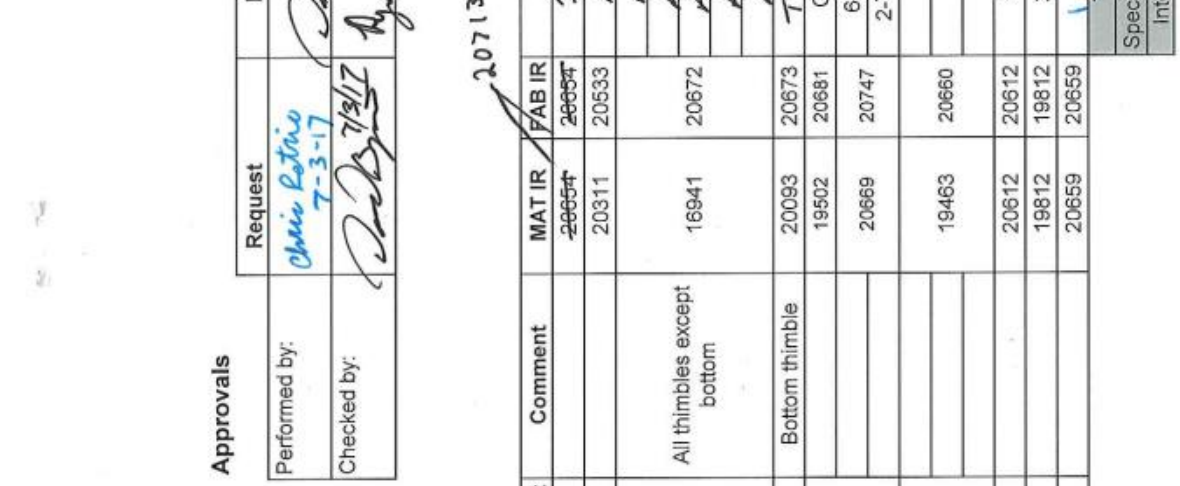

때

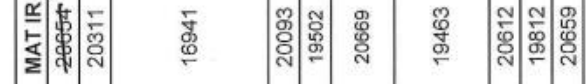
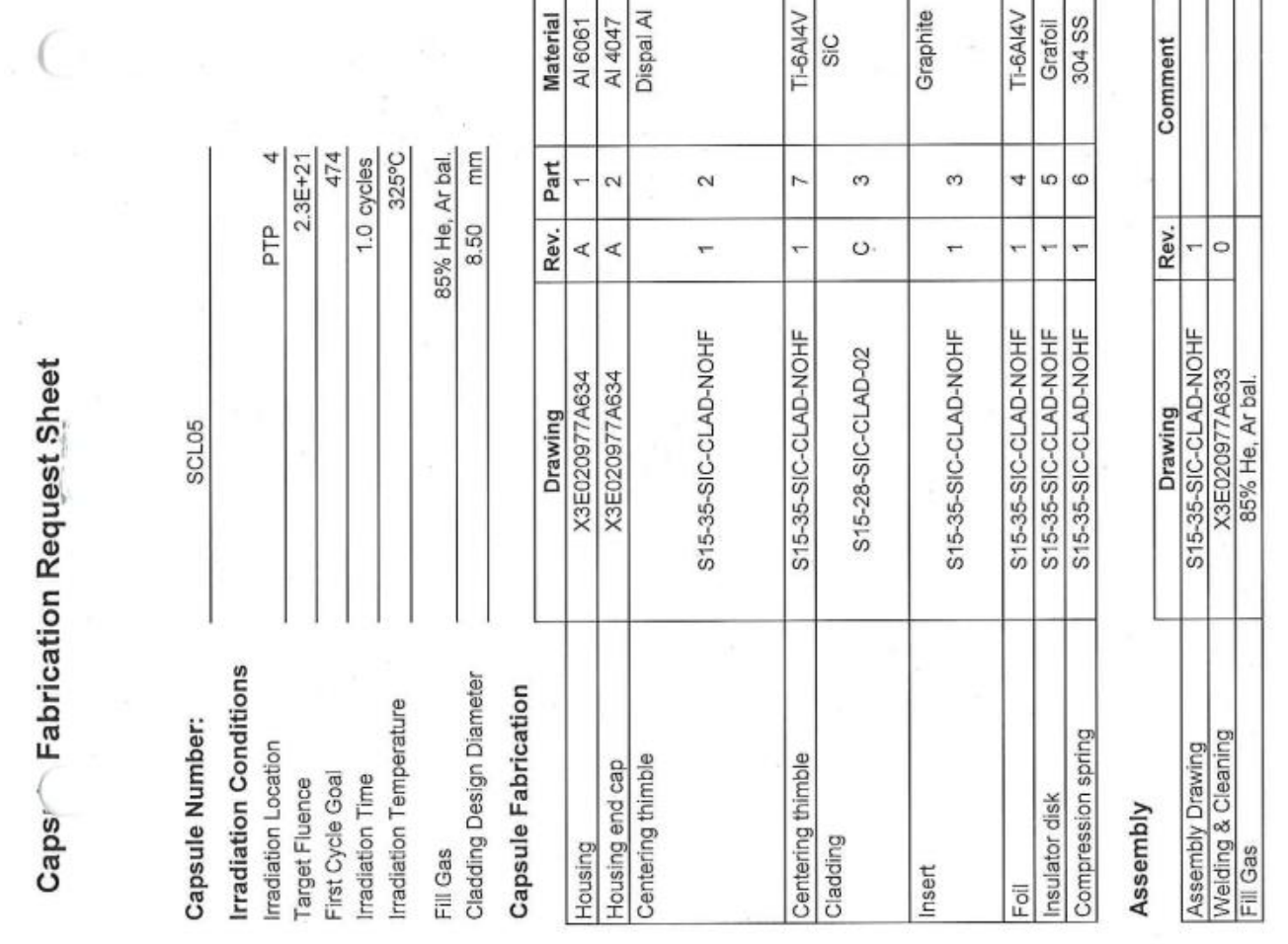
훙호ำ

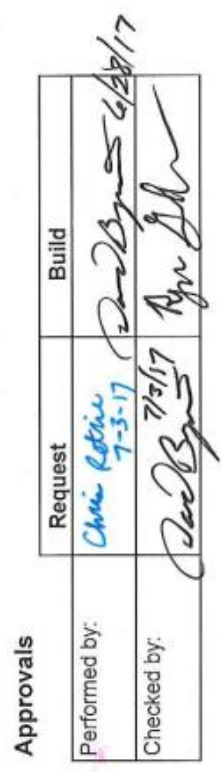

2.
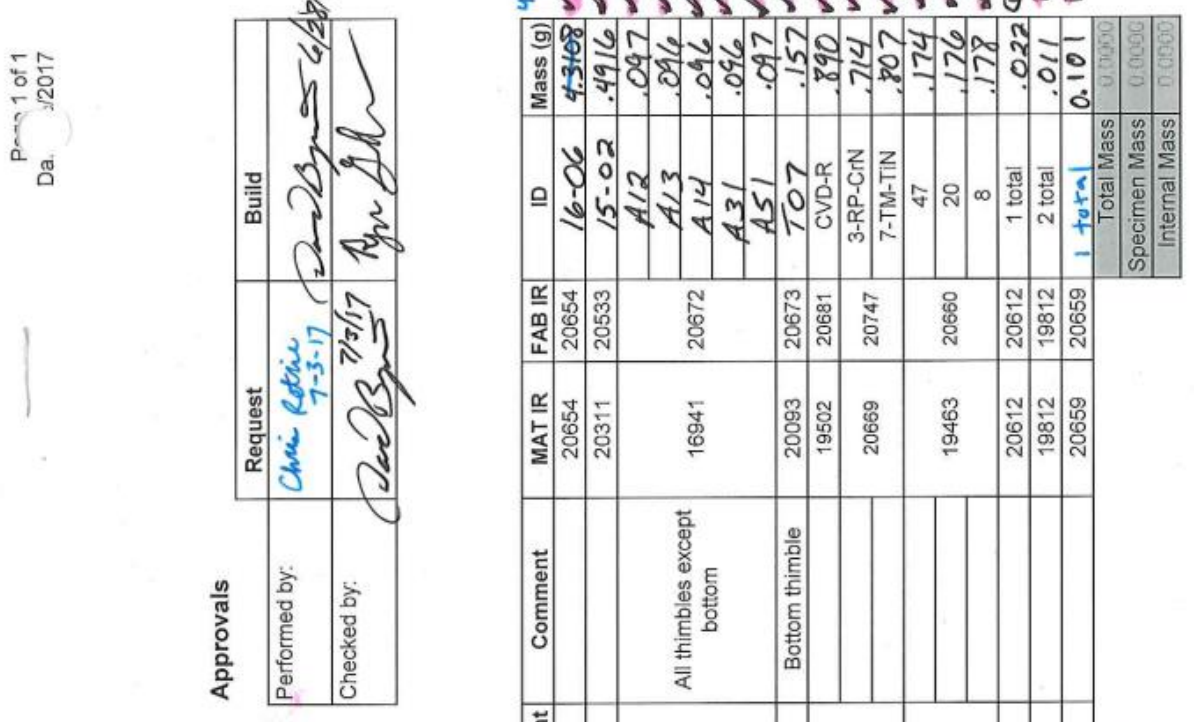


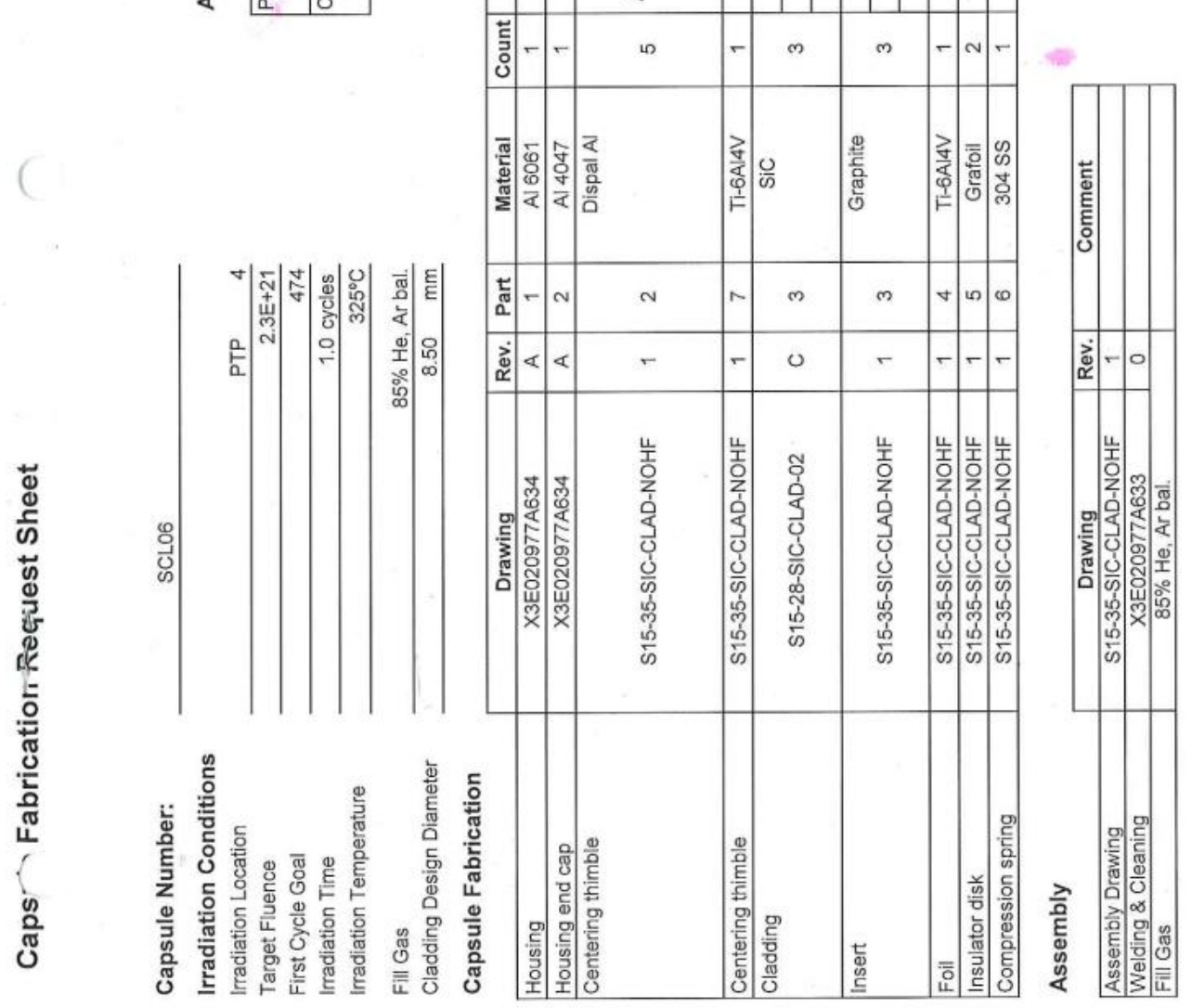

要 
Experiment Authorization Bases Document: EABD-HFIR-2009-004

Title: Rabbit Irradiations in the HFIR Target Region Prepared By: G. J. Hirtz

Date:01/12/2017

Rev 13

Page 10 of 36

\section{Section 6: Acceptance for Use of As-Built Experiment Capsule}

Note: This section is used to document acceptance of the as-built experiment for reactor installation and irradiation. This section is completed after completion of Section 2. See notes for explanation of signatures.

1. List Applicable Rabbit Identification and Heat Generation Classification (High or Low)

User I.D.

ATFS $C 03$

HFIR I.D.*

Heat Classification

ATFSCOY

ATFSC 05

ATFSCOb

ATFS $C 07$

ATFSC 08

ATTS 109

High

${ }^{*}$ Quality Assurance to verify correlation of User ID and HFIR ID noted above are consistent with markings presented on product body.

Independent Verification of User I.D. and HFIR I.D. :

2. Attach Capsule Fabrication Request Sheet or Equivalent: Chuis Refrie Lead Experimenter

3. Approvals (see notes for explanation of signature responsibilities)

Christian Petrie

Lead Experimenter

M.C.UANEE

Lead QA

L.C. Sm, $\%$

RRD QA

Greg Hirotz

RRD EA\&C'Staff

N.A. No NCS Requirements

RRD Criticality Safety Officer

N.A. No MBA Requirements HFIR MBA Representative

BRIAn E fuller

HFIR Operations (print name)
Chus Retric

Lead Experimenter (signature)

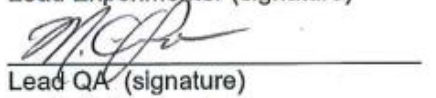

te $\mathrm{D}_{\text {mat }}$

RRD QA (signature)

Pend

RRD EA\&C Staff (signature)

N.A. No NCS Requirements RRD Criticality Safety Officer (signature)

N.A. No MBA Requirements HFIR MBA Representative (signature) Biem 27 illu HFIR Operations (signature)
$8-1-17$

Date

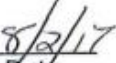

Date

$8 / 3 / 17$

Date

$8 / 11 / 17$

NA

Date

NA

Date

$\frac{8-15-17}{\text { Date }}$ 


\section{Section 6: Acceptance for Use of As-Built Experiment Capsule}

Note: This section is used to document acceptance of the as-built experiment for reactor installation and irradiation. This section is completed after completion of Section 2. See notes for explanation of signatures.

1. List Applicable Rabbit Identification and Heat Generation Classification (High or Low)

User I.D. HFIR I.D.* Heat Classification

$S(L O)$

SCLO2

SCLO3

$\mathrm{SCl}_{0} 4$

SCL 05

SCLOb

Law

* Quality Assurance to verify correlation of User ID and HFIR ID noted above are consistent with markings presented on product body. Independent Verification of User I.D. and HFIR I.D. : fe Smith

2. Attach Capsule Fabrication Request Sheet or Equivalent: Chris Retric Lead Experimenter

3. Approvals (see notes for explanation of signature responsibilities)

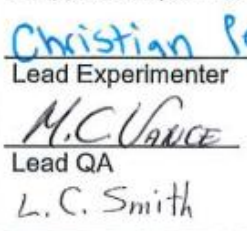

RRD QA

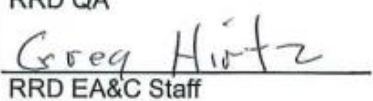

N.A. No NCS Requirements RRD Criticality Safety Officer

N.A. No MBA Requirements HFIR MBA Representative

FULLER, BRINW E HFIR Operations (print name)

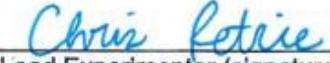

Lead Experimenter (signature)

$\frac{8-1-17}{\text { Date }}$

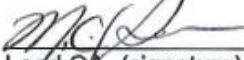

eadd QA (signature)

Il smith

RRD QA (signature)

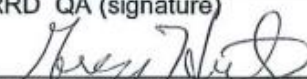

RRD EA\&C staff (signatu)e)

N.A. No NCS Requirements RRD Criticality Safety Officer (signature)

N.A. No MBA Requirements HFIR MBA Representative (signature)

Bime 27 ulln

HFIR Operations (signature)

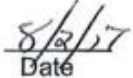

$8 / 3 / 17$

Date

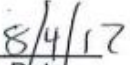

Date

NA Date

NA

Date

$08 / 15 / 2017$

Date 